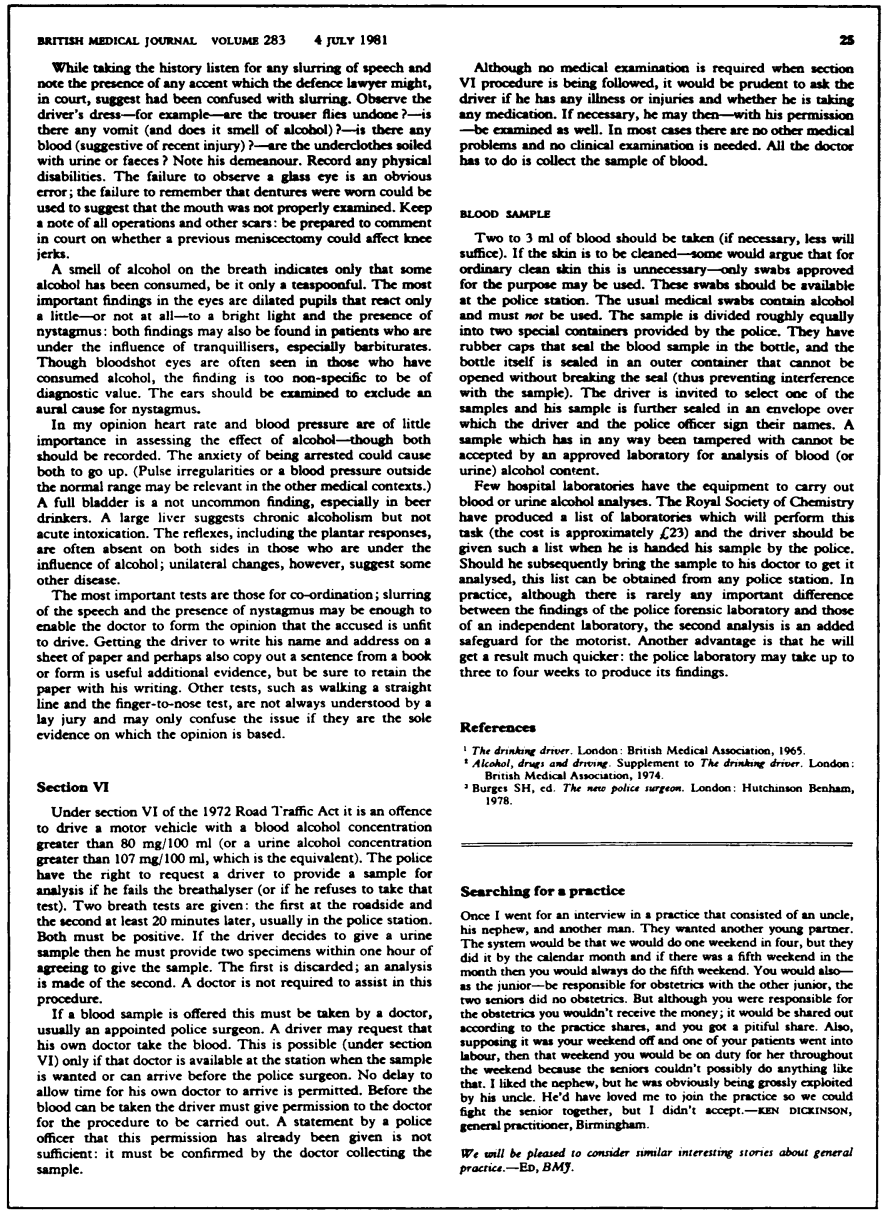

26

Unemployment in My Practice

\section{Rotherham}

M HAMID HUSAIN

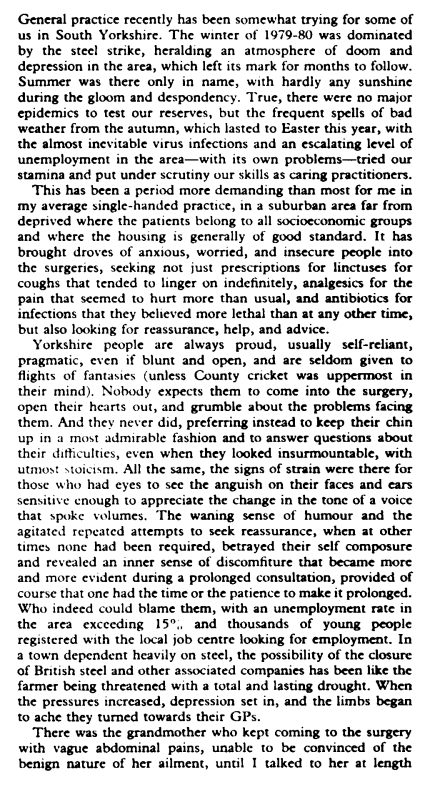

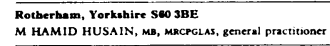

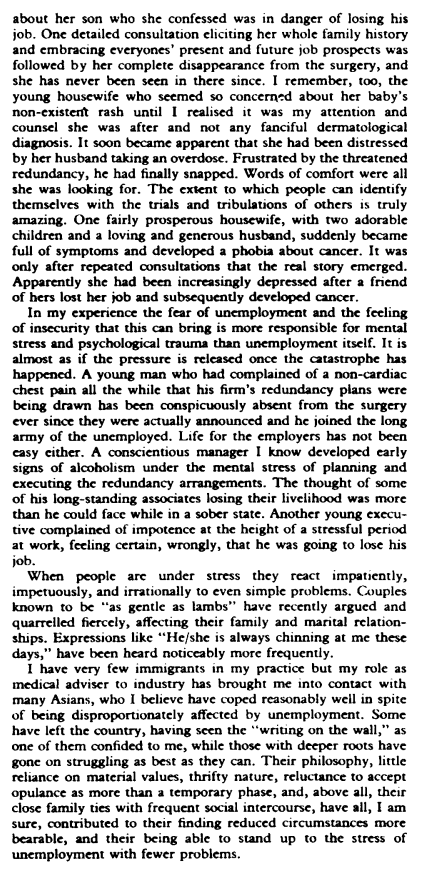

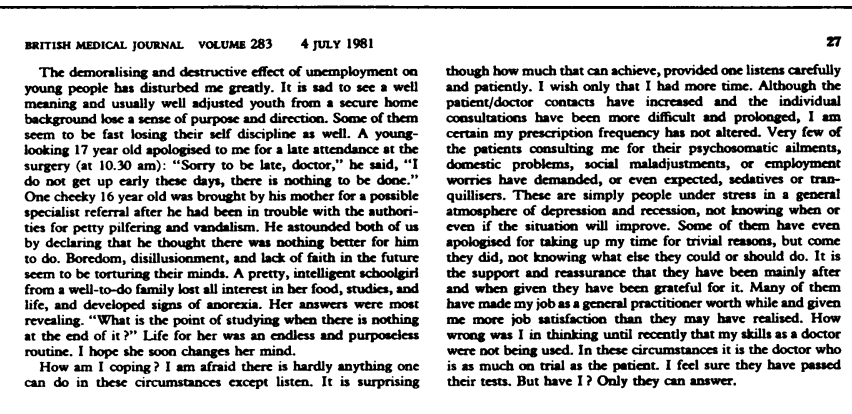

\title{
Emergencies in the Home
}

\section{Managing overdoses}

K C HINES

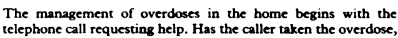

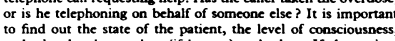

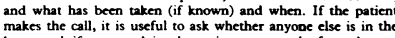

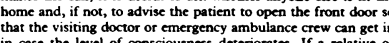

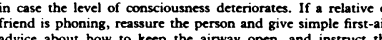

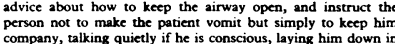
company, talking quietly if he is conscious, aying him down
the recoverery position if he becomes drowsy. It it is a great relic has baken an overdosese of mother's oral contraceptive pills will

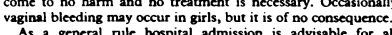

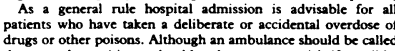

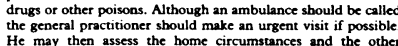

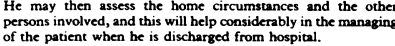

London E18 2AD
KC HINES, MS, ss, genceral pracititoner

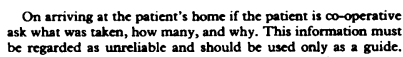
Relatives may eithere exaggerater or underplay the rists becauss

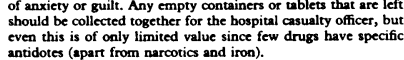
Treatmen

Emesis has almost no part to play in managing overdosese in
the home. Salinc and mustard emetics may be dengerous and

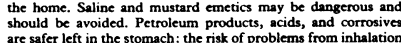

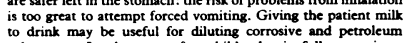

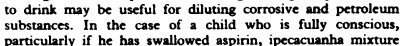

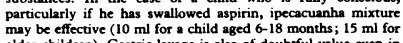

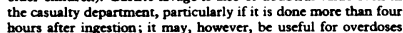

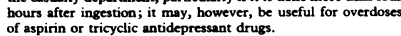

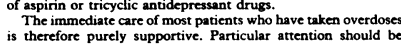

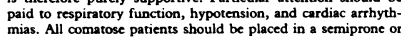
recovery position, using pillows or cushions when appropriatce.
An appropriate-sized oropharyngeal airway should be inserted

28

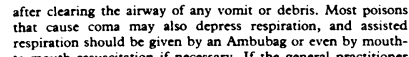
respiration should be given by an Ambubag or even by mouth-
to-mouth resuscititation if nececssary. If the general praccitioner

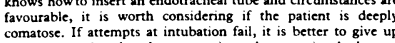

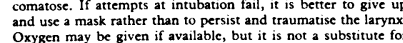
ventilation.
Shock accompanied by hypotension occurs most commonly in

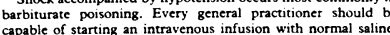

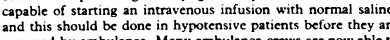
removed by ambulance. Many ambulance crews are now able
perform this simple procedure and may even intubate the patient for you if necessary.
Hypoohhermia commonly occurs in elderly patients who are in

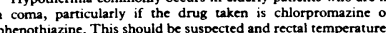
phenothiazine. This should be suspected and rectal temperatures
taken with a 1 isw-reading thermometer. The patient should be

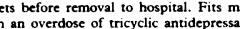
drugs snd may be controlled with intravenous diazepam or
intramuscular paraldehyde, but these drugs may further depress

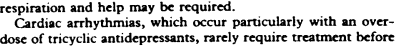

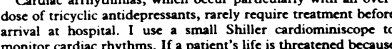

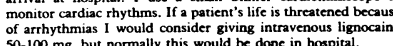

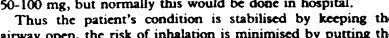

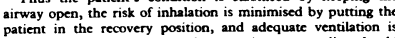

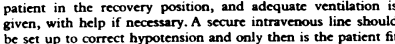

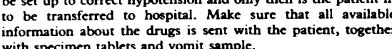
Common pitfalls

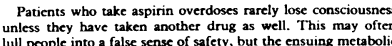

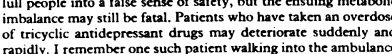

ONE HUNDRED YEARS AGO SIR - Abouc int Math

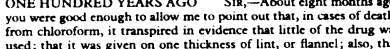

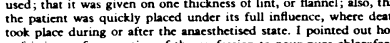

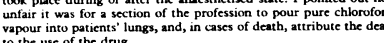

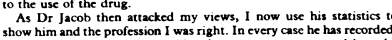

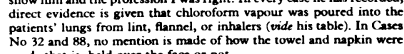

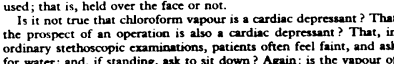

BRrTISH MEDTCA. JOURNAL VOLUMB $283 \quad 4$ JUTY 1981 but being deeply unconscious with a ventricular arthythmia on
arrivival at hospitial 20 minutues later. Herroin and morphine

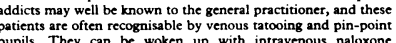

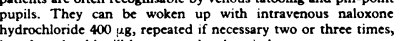

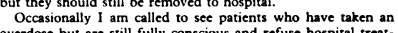

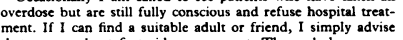
ment. If I can find a sutatible adult or fricend, I simply advise
that person about first-aid management. The ambulance crew and 1 would then wirthdraw wand would dexpect to be recalled later when the paticnt was too drowsy to complain.
Many overdosese are a cry for help, and a home visit is valuable in assessing the family dynamics, the conditions in which the
family is living, and other relevant problems. A lot of support may be needed by the family as well as the patient to combar All bencral pratcititiongers should carry the telephone number
of the National Poisons Information Service nearest their

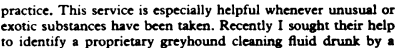
to identify a proptic
small child.

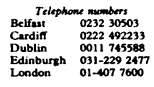

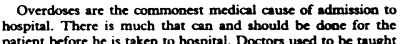

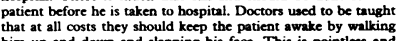
him up and down and slapping his facoc. This is pointless and

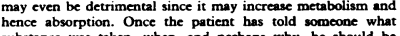

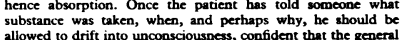

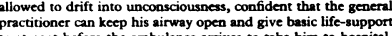

Bibliography

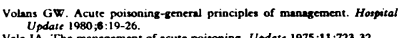

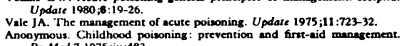

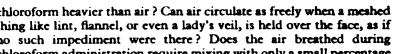

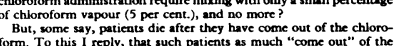

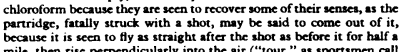

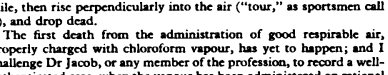

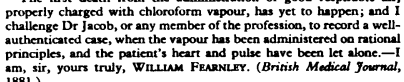

